\title{
Gender Diversity and the Choice of Conflict Management Styles in Small and Medium-Sized Enterprises
}

\author{
Ovidiu Niculae Bordean ${ }^{1, *(\mathbb{D})}$, Dalma Szonja Rácz ${ }^{1}$, Sebastian Ion Ceptureanu ${ }^{2}{ }^{(1)}$, \\ Eduard Gabriel Ceptureanu ${ }^{2}\left[\right.$ and Zenovia Cristiana Pop ${ }^{3}$ \\ 1 Department of Management, Babeș-Bolyai University, 400591 Cluj-Napoca, Romania; \\ dalma.racz@rodeapps.com \\ 2 Department of Management, The Bucharest University of Economic Studies, 010374 Bucharest, Romania; \\ sebastian.ceptureanu@man.ase.ro (S.I.C.); eduard.ceptureanu@man.ase.ro (E.G.C.) \\ 3 Department of Economics and Business Administration in German Language, Babeș-Bolyai University, \\ 400591 Cluj-Napoca, Romania; zenovia.pop@econ.ubbcluj.ro \\ * Correspondence: ovidiu.bordean@econ.ubbcluj.ro
}

Received: 1 August 2020; Accepted: 29 August 2020; Published: 1 September 2020

check for updates

\begin{abstract}
The current study investigates the relation between biological sex and gender role upon the choice of conflict management styles. The Bem Sex Role Inventory (BSRI) measured the gender role and Rahim Organizational Conflict Inventory-II (ROCI-II) Form C measured the conflict handling styles. Participants were employees of small and medium-sized enterprises (SMEs). The results found that biological sex has no correlation with the choice of conflict management style. On the other hand, the findings have shown that gender role is a predictor for the choice of conflict management styles as masculine individuals were highest on the dominating conflict style, whereas feminine individuals were highest on the avoiding style.
\end{abstract}

Keywords: biological sex; gender role; organizational conflict; conflict-management styles; small and medium-sized enterprises

\section{Introduction}

We deal with conflict and encounter conflictual situations on an almost daily basis, whether we are fully aware of it or not [1]. It could be that we are personally involved in these situations or simple bystanders, it could be a misunderstanding at home between spouses, a disagreement between friends, a clash among members of a group, or a rivalry between top management and other employees in the workplace. The possibilities are endless since conflict can take on many forms and can be encountered in numerous contexts.

Given the omnipresence of this phenomenon, as expected, a large number of articles, studies, and books have investigated the subject of conflict. The present study narrows down the research and focuses on organizational conflict, namely interpersonal conflict and conflict management within the work environment. In addition, it analyzes the connection between conflict and gender roles, how gender influences conflict, and the choice of a particular conflict resolution technique.

The inclusion of gender and gender role as a key factor in this research is mostly motivated by the increasing number of women entering the business environment in recent years, and the so-called feminization of the labor force in the twentieth century [2]. It is well known that women are faced with a number of challenges and obstacles when it comes to employment. Some examples worth mentioning are the absence of education and mentoring [3], and discrimination or stereotyping [4,5]. However, nowadays, we see a more gender-diversified work force. Consequently, the issue of whether 
there are indeed any significant gender contrasts within the capacity to oversee conflict has become a subject of important concern.

Consequently, the aim of the study is to answer the following research questions: (1) Does the biological sex of the individual influence the choice of conflict management styles of employees in the context of small and medium-sized enterprises in the north western part of Romania? (2) Does the gender identity of the individual influence the choice of conflict management styles of employees in the context of small and medium-sized enterprises in the north western part of Romania? and (3) Does the differentiation between biological sex and gender identity influence the findings regarding the choice of conflict management styles?

\section{Literature Review}

\subsection{Organizational Conflict}

Organizational conflict or workplace conflict can occur at various levels of an organization, and can take many forms. In addition, these types of conflicts can have numerous causes, including personal disagreements and differences in opinion to task-related issues. Regarding organizational conflict, six forms of conflict have been identified [6]: (1) intrapersonal (a form of internal struggle which occurs when an organizational member is required to perform certain tasks that do not match his or her expertise, goals, values, or interests); (2) interpersonal (occurring between two or more individuals within an organization); (3) intragroup (conflict between members of an organizational group); (4) intergroup (differences between groups with competing goals); (5) intraorganizational (generalized differences in goals or perceptions within an organization); and (6) interorganizational (conflict between two or more organizations competing for a similar goal).

Historically, three views of conflict have emerged [6,7]. The first was the so-called Classical View or Traditional View, which assumed that conflict in any form was a bad thing and had a negative impact upon organizations. It was believed that conflict arose from mistrust, lack of communication, and poor management. The Classical View proposed the total elimination or reduction in conflict in order to improve organizational efficiency. The ideal workplace was considered to be one in which there was no conflict. Subsequently, the Neo-Classical View or the Human Relations View arose between 1940 and 1970. It considered conflict to be something natural, which could not be totally eliminated from organizations, and should be accepted. This view encouraged the idea that conflict could be indeed beneficial at the organizational level. Finally, the Modern View or the Interactionist View emerged in the social science literature. This approach encourages conflict and considers it to be a positive marker of successful organizational administration. According to the modern view on organizational conflict, conflict is inevitable, legitimate, and within certain limits, can be an essential stimulating factor in terms of productivity.

Within the context of the workplace, there are numerous sources of conflict or clashes between employees. Members of the organization might support opposing positions, and have different values or opinions. In addition, compensation schemes, organizational culture, gender, power struggles, ego, jealousy, or pride could just as well be determinant factors that give rise to interpersonal conflicts at the organizational level. In essence, such interpersonal clashes cannot be considered a destructive or negative phenomenon. However, if they remain unresolved, or if the manner in which they are dealt with is not an appropriate one, they may have a severe negative impact upon relationships and interactions among employees [8,9].

Over the years, literature with regard to interpersonal conflict has recognized several typologies as can be seen in Table 1. The first model comprising five styles for handling interpersonal conflict in the context of organizations was developed by Follett [10]. This model recognized three main ways of dealing with conflict—domination, compromise, and integration-as well as two other secondary approaches - avoidance and suppression. Blake and Mouton [11] were the first to classify the modes of handling interpersonal conflict into five types: forcing, withdrawing, smoothing, compromising, 
and confrontation. This classification was based on two dimensions regarding the managers' attitudes: concern for production and concern for people. Thomas [12] reinterpreted and extended this model, and also found five ways of handling conflict, but his grid was derived from the individual's assertiveness and cooperativeness. Rahim and Bonoma's interpersonal conflict handling model involving five styles is based on both the classification of managerial styles proposed by Blake and Mouton and also the five modes model suggested by Thomas. Rahim and Bonoma [13] differentiated five styles of conflict management based on two basic dimensions-concern for self and concern for others. These dimensions show the motivational orientations of an individual during conflict. A combination of these two dimensions yielded the following five styles: integrating (i.e., involving collaboration between the parties), obliging (i.e., neglecting one's needs for the sake of the other party), dominating (i.e., trying to win at any cost as one ignores the needs of the other party), avoiding (i.e., refusing to acknowledge the existence of a conflict or running away from it), and compromising (i.e., giving up something in order to achieve a common goal).

Table 1. Styles of handling interpersonal conflict.

\begin{tabular}{lll}
\hline Proponents & Styles & Dimensions \\
\hline Follet [10] & $\begin{array}{l}\text { Domination, Compromise, Integration, } \\
\text { Avoidance, and Suppresion }\end{array}$ & NA \\
\hline Blake and Mouton [11] & $\begin{array}{l}\text { Forcing, Withdarwing, Smoothing, } \\
\text { Compromosing, and Confrontation }\end{array}$ & $\begin{array}{l}\text { Concern for production and concern for } \\
\text { people (Manager's attitude) }\end{array}$ \\
\hline Thomas [12] & $\begin{array}{l}\text { Colaborating, accomodating, Avoiding, } \\
\text { Competing, and Compromosing }\end{array}$ & $\begin{array}{l}\text { Cooperativeness and assertiveness } \\
\text { (Intention's of a party) }\end{array}$ \\
\hline Rahim and Bonoma [13] & $\begin{array}{l}\text { Integrating, Obliging, dominating, } \\
\text { Avoiding, and Compromosing }\end{array}$ & Concern for self and concern for others \\
\hline
\end{tabular}

The academic literature lacks a consensus about how an individual selects a particular conflict-handling style. Some say that people sometimes seem to adopt the style that they consider best fits a particular conflict situation [6]. On the other hand, experiments carried out by other researchers have concluded that the preference for a certain conflict-handling style is relatively stable with regard to the conflictual situation itself, and that it is actually mostly influenced by an individual's personality traits and characteristics $[14,15]$.

\subsection{Gender and Organizational Conflict}

Even though extensive research has already been done on the subject of the relationship between gender and the choice of conflict management style, this research has produced contradictory results. There are some authors who have found significant differences when it came to men and women's style of handling conflict [16], while others have concluded that there are no such differences [17,18], or if there are, they cannot be fully associated with gender, and may be motivated by other factors besides gender [19-21]. There is a strong belief that men and women significantly differ in their inclination and usage of conflict-handling styles. It has been proven that male employees tend to have a particular preference for competing strategies (dominating), whilst female employees are more likely to use non-competing strategies (avoiding, integrating, compromising) [19,22-28]. However, the main limitation of these studies is that they focused on assessing the biological sex of the respondents and did not take into consideration the gender role. Historically speaking, the terms "sex" and "gender" have been synonymous, but in today's society, they have come to bear significantly different meanings. The gender role can be defined as one's personal conception of oneself as being male, female, both, or neither. It is a measure of how people identify themselves psychologically, regardless of their biological sex. It is influenced equally by genetic and by external or environmental factors. On the other hand, biological gender or sex defines one's state of being male or female based on biological differences. Previous studies suggest that the gender role may determine how individuals react in particular 
circumstances [29]. Lately, researchers have been able to demonstrate that the gender role perspective is more suitable for explaining conflict management behavior. According to these studies, masculine individuals score higher on the dominating conflict style [30-33], whereas feminine individuals are highest on the avoiding conflict style [30,33]. Moreover, recent studies have pointed out that managers who are perceived by their subordinates as being androgynous will better deal with conflict situations than individuals reflecting masculine or feminine gender role types [34]. Moreover, there is evidence that suggests that the collaborating, accommodating, and the compromising styles are primarily preferred by androgynous individuals $[29,32,35]$. Therefore, our specific research hypotheses are:

Hypothesis 1 (H1). Biological sex does not have an influence on any of the conflict management styles.

Hypothesis 2 (H2). Masculine individuals will rate themselves higher on the dominating conflict style.

Hypothesis 3 (H3). Feminine individuals will rate themselves higher on the avoiding conflict style.

Hypothesis 4 (H4). Androgynous individuals will rate themselves lower on the dominating conflict style.

\section{Methodology}

\subsection{Measurement}

In order to measure the gender identity of the respondents, the Bem Sex-Role Inventory-a measure of masculinity-femininity and gender roles-was used [36]. It assesses how people identify themselves psychologically, regardless of their biological sex. It assesses masculinity and femininity based on the respondent's self-reported possession of some socially-desirable and stereotypically masculine or feminine personality characteristics. The instrument consists of 60 adjectives divided into three distinct categories of 20 adjectives each: masculine, feminine, and social desirability. The participants were asked to rate themselves on these personality traits based on a seven-point Likert scale. The results of the Bem Sex-Role Inventory will include each individual in one of the following four categories: masculine, feminine, androgynous, and undifferentiated. A masculine or feminine role is given by scoring above the median in one gender and below the median in the other. Above the median scores in both masculine and feminine categories will yield an androgynous result, while an undifferentiated result is given by scoring below the median in both categories.

For the purpose of measuring the conflict-handling styles of the participants, the Rahim Organizational Conflict Inventory II (ROCI II) was employed [37]. The instrument is a standardized questionnaire containing 28 statements. Each item is rated on a five-point Likert scale. A higher score indicates greater use of a conflict-handling style. ROCI-II was designed to measure five independent categories of styles for managing interpersonal conflict: integrating (7 statements), obliging (6 statements), dominating (5 statements), avoiding (6 statements), and compromising (4 statements).

\subsection{Data Collection}

The questionnaire was distributed individually via e-mail to each of the participants. The e-mails also contained brief explanations regarding the purpose and nature of the research together with some instructions for filling out the questionnaires. Google Forms was used to incorporate all three questionnaires (ROCI-II Form C, BSRI, and general questions) into a single one for easy distribution and also in order to be able to gather all of the information from the respondents in a single bulk of data.

Since both questionnaires are self-administering, all the participants were asked to complete them individually. There was no time limit given for completing the questionnaires. However, individuals were advised not to spend too much time focusing on a particular item. Moreover, all participants were 
informed that anonymity would be maintained, and that the research would present only summarized data. In order to complete the ROCI-II questionnaire, respondents were asked to think about a conflict situation in which they and their peers were involved.

From the time of distribution of the questionnaire, a period of 3 weeks was given for completion. By using a disproportionate stratified sampling technique, we selected 300 companies that met the definition of SMEs in both European and Romanian legislation [38]. According to the existing regulations, the SME sector comprises three categories: micro (up to ten employees and turnover of up to 2 million Euro), small (from ten up to fifty employees and a turnover of up to 10 million Euro), and medium-size enterprises (from fifty employees up to two hundred and fifty and a turnover of up to 50 million Euro). Out of the 300 questionnaires distributed, 72 responses were received, giving us an overall response rate of $24 \%$. We used a convenience sampling technique in order to ensure representation of the 300 small and medium-sized enterprises identified in a demarcated area in the north western part of Romania. The response rate of useable questionnaires is acceptable considering that low response rates are common in small business research. For example, a previous similar study had a usable sample of 59 [39], whereas another had a usable sample of 56 [40].

\subsection{Participants}

The final sample includes organizations from different industries in order to avoid the situation in which organizational culture might influence the findings. Responses were admissible as data only when participants completed all of the questions. All the organizations included were randomly chosen small and medium-sized enterprises, all of which fall into one of the following 3 categories: information technology, medicine, and economics. Table 2 presents a summary of all of the demographic data gathered via the first part of our questionnaire. It is worth mentioning that the IT sector represents one of the main development engines of the north west region, and the number of SMEs in this sector is growing exponentially in this region. Biographical data indicated that $59.72 \%$ of the respondents were male. Participants who had previous work experience of 1 and 3 years totalled $70.83 \%$, and those with previous work experience of more than 3 years but less than 7 years, $12.50 \%$. Respondents came from different age groups, $73.61 \%$ being younger than 25 years, those between 25 and 30 totalling $18.05 \%$, and $6.94 \%$ being older than 31 years.

Table 2. Demographics of respondents.

\begin{tabular}{cccccc}
\hline & & \multicolumn{2}{c}{ Male } & \multicolumn{2}{c}{ Female } \\
\cline { 3 - 6 } & & \multicolumn{2}{c}{$\boldsymbol{n}=\mathbf{4 3}$} & \multicolumn{2}{c}{$n=\mathbf{2 9}$} \\
\cline { 3 - 6 } & & $\boldsymbol{n}$ & $\%$ & $\boldsymbol{n}$ & $\%$ \\
\hline \multirow{3}{*}{ Age group } & Younger than 25 & 35 & 81.40 & 18 & 62.07 \\
& 25-30 & 7 & 16.28 & 6 & 20.69 \\
& Older than 30 & 1 & 2.33 & 5 & 17.24 \\
\hline \multirow{3}{*}{ Field of work } & Information & 40 & 93.02 & 19 & 65.52 \\
& technology & 1 & 2.33 & 7 & 24.14 \\
& Economic & 2 & 4.65 & 3 & 10.34 \\
\hline \multirow{3}{*}{ Work experience } & Medical & 2 & 4.65 & 0 & 0 \\
(in years) & Less than 1 & 32 & 74.42 & 19 & 65.52 \\
& $1-3$ & 7 & 16.28 & 2 & 6.90 \\
& $4-6$ & 2 & 4.65 & 5 & 17.24 \\
& $7-9$ & 0 & 0 & 1 & 3.45 \\
& $10-12$ & 0 & 0 & 2 & 6.90 \\
\hline
\end{tabular}




\subsection{Data Analysis}

In order to determine the internal consistency of the questionnaires, we used Cronbach's alpha. The computed Cronbach alphas for this study were consistent with previous findings: 0.856 (Masculinity), 0.826 (Femininity), 0.552 (Androgyny). In addition, in the case of the Bem Sex-Role Inventory, a large number of previous studies have found adequate test-retest and internal consistency coefficients for the ROCI-II. The Cronbach's alphas computed for our study were consistent with those previously reported: 0.794 (Collaborating), 0.703 (Accommodating), 0.770 (Competing), 0.812 (Avoiding), and 0.863 (Compromising). In order to determine whether biological sex and gender role have any influence upon the choice of conflict management style, we used correlation analysis as a method of statistical evaluation to quantify the relationship between these variables. Moreover, with the help of regression analysis, we assessed the cause of effect of these relationships between the variables. Eventually, in order to compare the means of the samples, we used the one-way analysis of variance (one-way ANOVA).

\section{Results}

With the help of the Bem Sex-Role Inventory, by using the median split method, we were able to categorize the participants as masculine, feminine, androgynous, or undifferentiated. The scales for masculinity, femininity, and androgyny are comprised of 20 masculine, 20 feminine, and 20 androgynous attributes, respectively.

The results for the BSRI questionnaire can be seen in Table 3. The overall results show that the majority of the respondents (44.44\%) fall into the undifferentiated category, followed by the masculine one with $29.17 \%$. However, if we consider the BSRI results reported with regard to the participant's gender, we notice that in the case of males, almost half of the individuals $(46.51 \%)$ were characterized as being masculine. On the other hand, the female group of participants seem to follow the overall trend, with more than half of them $(62.07 \%)$ being part of the undifferentiated category. Moreover, in the case of females, only $3.45 \%$ of them were characterized as being masculine.

Table 3. Bem Sex-Role Inventory results.

\begin{tabular}{ccccccc}
\hline & \multicolumn{2}{c}{ Male } & \multicolumn{2}{c}{ Female } & \multicolumn{2}{c}{ Total } \\
\cline { 2 - 7 } & $\boldsymbol{n}=\mathbf{4 3}$ & $\mathbf{5 9 . 7 2 \%}$ & $\boldsymbol{n = 2 9}$ & $\mathbf{4 0 . 2 8 \%}$ & \multicolumn{2}{c}{$\boldsymbol{n = 7 2}$} \\
\cline { 2 - 7 } & $\boldsymbol{n}$ & $\mathbf{\%}$ & $\boldsymbol{n}$ & $\mathbf{\%}$ & $\boldsymbol{n}$ & $\mathbf{\%}$ \\
\hline Masculine & 20 & 46.51 & 1 & 3.45 & 21 & 29.17 \\
Feminine & 4 & 9.30 & 6 & 20.69 & 10 & 13.89 \\
Androgynous & 5 & 11.63 & 4 & 13.79 & 9 & 12.50 \\
Undifferentiated & 14 & 32.56 & 18 & 62.07 & 32 & 44.44 \\
\hline
\end{tabular}

Intercorrelations for biological sex, conflict handling styles and the raw scores on the two Bem Sex-Role Inventory scales, masculinity and femininity, are shown in Table 4. As in the case of most of the studies carried out previously, we found that there was no correlation between the biological sex of an individual and his/her choice of a specific conflict management style.

When controlling for gender identity, our research shows significant correlations between this and several of the conflict management styles. A BSRI result of masculinity seems to be positively correlated with the choice of competing/dominating conflict management style (0.505) at $p<0.01$. On the other hand, it is also negatively correlated with the avoiding style $(-0.260)$. The results clearly indicate that BSRI femininity is positively correlated with accommodating $(0.364)$ and collaborating conflict handling styles $(0.334)$ at $p<0.01$. BSRI masculinity and femininity are indeed correlated with an individual's choice of conflict management style. 
Table 4. Correlations between biological sex, BSRI masculinity and femininity raw scores, and conflict management styles.

\begin{tabular}{cccccccc}
\hline Variables & $\mathbf{1}$ & $\mathbf{2}$ & $\mathbf{3}$ & $\mathbf{4}$ & $\mathbf{5}$ & $\mathbf{6}$ & $\mathbf{7}$ \\
\hline 1. Biological sex & 1 & & & & & & \\
2. Masculinity & $0.384^{* *}$ & 1 & & & & & \\
3. Femininity & -0.173 & 0.113 & 1 & & & & \\
4. Collaborating & 0.002 & 0.118 & $0.334^{* *}$ & 1 & & & \\
5. Accomodating & 0.095 & -0.077 & $0.364^{* *}$ & $0.374^{* *}$ & 1 & & \\
6. Competing & 0.144 & $0.505^{* *}$ & -0.016 & -0.130 & -0.180 & 1 & 0.079 \\
7. Avoiding & 0.094 & $-0.260^{*}$ & 0.121 & 0.032 & $0.0476^{* *}$ & 0.031 \\
8. Compromising & 0.111 & -0.003 & 0.036 & $0.405^{* *}$ & $0.298^{*}$ & 0.041 & 0.148 \\
\hline
\end{tabular}

In order to further examine the effects of gender role on conflict handling style, we carried out a one-way ANOVA analysis (Table 5). The results revealed significant gender identity main effects for collaborating, $\mathrm{F}(3,68)=3.036, p<0.05$, accommodating, $\mathrm{F}(3,68)=3.140, p<0.05$, and competing, $\mathrm{F}(3,68)=4.373, p<0.01$ conflict management styles. No significant gender role main effects were identified for avoiding, $\mathrm{F}(3,68)=1.575$, ns, or compromising, $\mathrm{F}(3,68)=0.827$, ns. Moreover, with regard to the collaborating style, we found significant differences between the androgynous and undifferentiated groups. The analysis also revealed important differences between the masculine and feminine group on the accommodating style, and between masculine and undifferentiated groups when it came to the competing style.

Table 5. ANOVA results.

\begin{tabular}{|c|c|c|c|}
\hline \multirow[t]{2}{*}{ Dependent Variables } & \multicolumn{2}{|c|}{$\begin{array}{l}\text { Independent Variable } \\
\text { (Gender Role: Masculine, Feminine, } \\
\text { Androgynous, Undifferentiated) }\end{array}$} & \multirow[t]{2}{*}{ Tukey HSD } \\
\hline & $\mathbf{F}$ & Sig. & \\
\hline Collaborating & 3.036 & 0.035 & Androgynous $\rightarrow$ Undifferentiated * \\
\hline Accommodating & 3.140 & 0.031 & Masculine $\rightarrow$ Feminine ${ }^{*}$ \\
\hline Competing & 4.373 & 0.007 & Masculine $\rightarrow$ Undifferentiated ${ }^{* *}$ \\
\hline Avoiding & 1.575 & 0.204 & \\
\hline Compromising & 0.827 & 0.424 & \\
\hline
\end{tabular}

In addition, a regression analysis having biological sex, masculinity, femininity, and androgyny as independent variables, and the five conflict management styles as the dependent variables, was conducted (Table 6). The findings indicate that biological sex has no influence upon the choice of conflict management style. On the other hand, BSRI masculinity $(\beta=1.776, p<0.05)$ and androgyny ( $\beta=1.824, p<0.05)$ were found to predict a significant $28.9 \%$ of variance in the competing style $(\mathrm{F}=3.555, p<0.05)$. Therefore, we can conclude that masculine and androgynous individuals will have a tendency to use a dominant conflict-handling style. In addition, the avoiding style is positively influenced by BSRI femininity $(\beta=1.919, p<0.05)$ in a model that accounts for $20.1 \%$ of the variance. Hence, this proves that the first three hypotheses were supported, whereas the last one was rejected. 
Table 6. Results of the regression analysis.

\begin{tabular}{cccccc}
\hline Independent Variables & \multicolumn{5}{c}{ Dependent Variables } \\
\hline & Collaborating & Accommodating & Competing & Avoiding & Compromising \\
Biological sex & $-0.114(-0.633)$ & $0.074(0.434)$ & $-0.073( \pm 0.256)$ & $0.307(0.978)$ & $0.036(0.133)$ \\
Masculinity & $-0.436(-0.889)$ & $-0.112(-0.244)$ & $1.766(2.268)^{*}$ & $1.309(1.537)$ & $-0.170(-0.230)$ \\
Femininity & $-0.224(-0.468)$ & $0.419(0.933)$ & $0.970(1.277)$ & $1.919(2.309)^{*}$ & $0.024(0.033)$ \\
Androgyny & $-0.158(-0.317)$ & $0.420(0.897)$ & $1.824(2.299)^{*}$ & $1.449(1.670)$ & $0.224(0.298)$ \\
Model F & 1.198 & 3.610 & 3.555 & 2.199 & 0.454 \\
$\mathrm{R}^{2}$ & 0.120 & 0.292 & 0.289 & 0.201 & 0.049 \\
Adjusted $\mathrm{R}^{2}$ & 0.020 & 0.211 & 0.208 & 0.109 & 0.059 \\
\hline
\end{tabular}

${ }^{*} p<0.05$, (Values in parentheses represent $t$-values).

\section{Discussion}

The field of gender-related differences in conflict management styles still remains an area dominated by ambiguity. Despite the large number of studies available, there still remain many unanswered questions. Our aim was to add value to the currently available research on this topic, by not only considering biological gender as an influencing factor, but also by taking into consideration the individuals' gender role which can develop according or not to the gender assigned at birth. The results indicate that the gender role variable is perhaps less used-and possibly less understood-in the business environment, and is more relevant than the biological sex variable in determining the choice of conflict-handling styles. Therefore, by analysing the links between the male and female gender role, we shed light on the significant variations in ways of handling conflict between men and women that are not purely attributable to biological (i.e., sex-related) reasons, but are clarified, at least to some extent, through the impact of gender-related influences embedded within a specific culture, family, and social structure. Therefore, we do not question the existence of biological sex, and replace it with an arbitrary gender role, but with one's internal sense of self. In order to enhance the entry and development possibilities of gender non-conforming individuals within SMEs, it is necessary to expand our knowledge of the conflict-handling style patterns by analyzing the gender-role-unique potential.

Consistent with previous studies [30-32], the results show that there is a congruence between the BSRI masculinity and the competing/dominating conflict management styles. In addition, the BSRI feminine orientation is more likely to be related to the avoiding conflict handling style, whereas androgynous orientation is associated with the dominating handling style. There are several implications for understanding the gender diversity in conflict management styles. Firstly, the preference for the avoiding style on the part of feminine individuals could be explained through a reluctance to deal with issues related to personal interests. This is the case when individuals with a feminine orientation have to stand up for themselves when facing conflicts, or when they have to negotiate on their own behalf [41]. Romania is known as a country that historically has supported pay differentiation based on gender [42], thus creating a large variation in occupational wages between male and female workers. Moreover, recent findings [43] suggest that females with collectivistic traits, like the one included in our sample, prefer a problem-solving approach to conflict rather than a competing one [24]. Secondly, in a workplace context, team composition plays a key role for the overall dynamics and effectiveness of the team. As masculine and feminine individuals have opposing views on conflict-handling styles, it is important to plan for an adequate team composition so that conflict will be managed properly. This implies that companies will find strategies not to eliminate organizational conflict, but rather to manage it so that both individual and organizational effectiveness will increase [26,44]. Thirdly, the results call for more action through which companies can enhance the conflict management skills of their employees. Promoting an organizational culture that will embrace diversity has better chances to improve the level of collaboration among its members with positive effects on personnel retention. Moreover, in order to counteract the negative effects of conflict, and to be able to take advantage of its positive effects, appropriate conflict management styles need to be adopted and proper conflict management techniques must be employed. It is considered that good conflict resolution 
ability will lead to better performance, a healthier work environment, and better employee retention. If avoided and not properly dealt with, conflict can lead to job dissatisfaction, job stress, distrust, reduced performance, and can affect organizational commitment and loyalty.

An important aspect of this study was the focus on the employees of small and medium-sized enterprises. Previous studies of small businesses pointed to similar findings, showing that most of the family business owners made use of the dominating style to solve conflicts, whereas compromising was used to a lesser extent $[39,40,45]$. At the same time, the ability of managers to resolve conflict could prove an important skill that could help a company to gain a competitive advantage. For small and medium-sized enterprises, this could be of tremendous importance, since recent studies [46] suggest that masculinity cultures tend to favor entrepreneurship activities.

\section{Conclusions}

This article examined the relationship between gender roles, biological sex, and conflict management styles in the context of the workplace. It is important for two fundamental reasons. The first one is the research context of this study: small and medium-sized enterprises in Romania. So far, there have been very few studies carried out for small and medium-sized enterprises in order to analyze the significance of gender roles in terms of conflict and conflict resolution styles $[39,40]$. Secondly, the paper takes into consideration not only the biological sex of the participants, but also their measure of masculinity-femininity and gender roles. The findings are in line with the socialization perspective, one of the dominant theoretical approaches in gender role research [47]. According to this theory, gender role orientation is a strong predictor of behavior [32].

Besides recognizing the findings obtained as a result of the present study, we should also acknowledge some of its limitations. As mentioned, the majority of the organizations that were involved in this study were part of the information technology world. Therefore, it would obviously be useful to replicate this work in different organizational settings. In addition, besides including organizations from different domains of activity, it would be helpful to carry out the research on a larger number of subjects and also extend it to other geographical areas. Studies focusing on the perceptions of respondents are known for their low response rate [48]. The questionnaires were filled in anonymously by the respondents, assuring in this way that the biases of social desirability associated with taking part in the survey were kept to a minimum. By conducting the questionnaires on respondents from different countries, it could also be insured that local cultures, values, and beliefs do not influence the final results of the research. Finally, a more in-depth analysis could be made if the research also included other factors besides biological sex and gender role. Other variables that might be considered along with biological sex and gender identity could be the individual's age, educational background, organizational status, and so on. The research could then determine whether or not these influence the choice of conflict management style, and could also investigate if the overall results in terms of biological sex and gender role differ from the ones presented in this study.

The significance of this paper lies in the context and approaches used for the research and, despite the limitations mentioned above, its findings will add value to the already-available expertise regarding conflict and conflict management techniques. In addition, it will hopefully encourage the development of further similar studies in other developing countries, as the knowledge base obtained so far relies mostly on experiments carried out in economically and culturally well-developed countries.

Author Contributions: Conceptualization, O.N.B. and D.S.R.; formal analysis, O.N.B., D.S.R., S.I.C., E.G.C. and Z.C.P.; methodology, O.N.B. and D.S.R.; resources, S.I.C., E.G.C. and Z.C.P.; writing-original draft preparation, O.N.B. and D.S.R.; writing-review and editing, O.N.B., D.S.R., S.I.C., E.G.C. and Z.C.P. All authors have read and agreed to the published version of the manuscript.

Funding: This research received no external funding.

Conflicts of Interest: The authors declare no conflict of interest. 


\section{References}

1. Augsburger, D.W. Conflict Mediation across Cultures: Pathways and Patterns; Westminster John Knox Press: Louisville, KY, USA, 1992.

2. Armstrong, P. The feminisation of the labour force: Harmonizing down in a global economy. In Rethinking Restructuring: Gender and Change in Canada; Bakker, I., Ed.; University of Toronto Press: Toronto, ON, Canada, 1996; pp. 29-54.

3. Stead, V.; Elliott, C.J. Women's Leadership; Palgrave Macmillan: Basingstoke, UK, 2009.

4. Reid, M.F.; Allen, M.W.; Armstrong, D.J.; Riemenschneider, C.K. Perspectives on challenges facing women in IS: The cognitive gender gap. Eur. J. Inform. Syst. 2010, 19, 526-539. [CrossRef]

5. Wilkinson, G. Women in Business; Gulf Business: Dubai, UAE, 1996.

6. Rahim, A.M. Managing Conflict in Organizations, 4th ed.; Routledge: New York, NY, USA, 2015.

7. Robbins, S. Organizational Behavior, 11th ed.; Prentice Hall: Upper Saddle River, NJ, USA, 2005.

8. De Dreu, C.K.W.; Van Vianen, A.E.M. Responses to relationship conflict and team effectiveness. J. Organ. Behav. 2001, 22, 309-328. [CrossRef]

9. Pelled, L.H.; Eisenhardt, K.M.; Xin, K.R. Exploring the black box: An analysis of work group diversity, conflict, and performance. Admin. Sci. Quart. 1999, 44, 1-28. [CrossRef]

10. Follett, M.P. Constructive conflict. In Dynamic Administration: The Collected Papers of Mary Parker Follett; Metcalf, H.C., Urwick, L., Eds.; Harper \& Row: New York, NY, USA, 1940; pp. 30-49.

11. Blake, R.R.; Mouton, J.S. The Managerial Grid; Gulf Publishing: Houston, TX, USA, 1964.

12. Thomas, K.W. Conflict and conflict management. In Handbook of Industrial and Organizational Psychology; Dunnette, M., Ed.; Rand McNally: Chicago, IL, USA, 1976; pp. 889-935.

13. Rahim, M.A.; Bonoma, T.V. Managing organizational conflict: A model for diagnosis and intervention. Psychol. Rep. 1979, 44, 1323-1344. [CrossRef]

14. Antonioni, D. Relationship between the Big Five personality factors and conflict management style. Int. J. Confl. Manag. 1998, 9, 336-355. [CrossRef]

15. Moberg, P.J. Predicting conflict strategy with personality traits: Incremental validity and the five factor model. Int. J. Confl. Manag. 1998, 9, 258-285. [CrossRef]

16. Merchant, K. How Men and Women Differ: Gender Differences in Communication Styles, Influence Tactics, and Leadership Styles. CMC Senior Theses Paper 513. 2012. Available online: https://scholarship.claremont. $\mathrm{edu} / \mathrm{cgi} /$ viewcontent.cgi? article $=1521 \&$ context $=$ cmc_theses (accessed on 10 June 2020).

17. Odetunde, O.J. Influence of transformational and transactional leaderships, and leaders' sex on organisational conflict management behaviour. Gender Behav. 2013, 11, 5323-5335.

18. Sogra, K.J. The Impact of Gender Differences on the Conflict Management Styles of Managers in Bangladesh: An Analysis; Cambridge Scholars Publishing: Newcastle, UK, 2014.

19. Korabik, K.; Baril, G.L.; Watson, C. Managers' conflict management style and leadership effectiveness: The moderating effects of gender. Sex Roles 1993, 29, 405-420. [CrossRef]

20. Oftedal, A.; Kang, H.; Schneider, I. Perceptions and Responses to Conflict: Comparing Men and Women in Recreational Settings; Taylor \& Francis Group: London, UK, 2015.

21. Jing, L.; Ma, Z.; Ma, Z.; Chen, B.; Cheng, S. Nurse Practitioners' Work Values and Their Conflict Management Approaches in a Stressful Workplace: A Taiwan Study. Sustainability 2020, 12, 1040. [CrossRef]

22. Blackburn, C.H.; Martin, B.N.; Hutchinson, S. The role of gender and how it relates to conflict management style and school culture. J. Women Educ. Leadersh. 2006, 4, 32-41.

23. Brahnam, S.D.; Margavio, T.M.; Hignite, M.A.; Barrier, T.B.; Chin, J.M. A gender-based categorization for conflict resolution. J. Manag. Dev. 2005, 24, 197-208. [CrossRef]

24. Holt, J.L.; DeVore, C.J. Culture, gender, organizational role, and styles of conflict resolution: A meta-analysis. Int. J. Intercult. Rel. 2005, 29, 165-196. [CrossRef]

25. Patre, S.R. Are conflict management styles of gen Y related to their socio-demographic characteristics? Glob. J. Manag. Bus. Res. 2017, 17, 54-65.

26. Rahim, M.A.; Katz, J.P. Forty years of conflict: The effects of gender and generation on conflict-management strategies. Int. J. Confl. Manag. 2020, 31, 1-16. [CrossRef]

27. Thomas, K.W.; Thomas, G.N.; Schaubhut, N. Conflict styles of men and women at six organization levels. Int. J. Confl. Manag. 2008, 19, 148-166. [CrossRef] 
28. Vokić, N.; Sontor, S. onflict Management Styles in Croatian Enterprises-The Relationship between Individual Characteristics and Conflict Handling Styles; Working Paper Series, 09-05; Faculty of Economics and Business, Zagreb: Zagreb, Croatia, 2009. Available online: http://web.efzg.hr/repec/pdf/Clanak\%2009-05.pdf (accessed on 25 July 2020).

29. Cook, E.P. Psychological Androgyny: A review of the research. Couns. Psychol. 1987, 15, 471-513. [CrossRef]

30. Brewer, N.; Mitchell, P.; Weber, N. Gender role, organization status, and conflict management styles. Int. J. Confl. Manag. 2002, 13, 78-94. [CrossRef]

31. Brusko, L. Organized Chaos: A Survey of Conflict Management Strategies, Gender Roles, and Status in an Organizational Setting, UW-L Journal of Undergraduate Research XIII. 2010. Available online: https://www.uwlax.edu/globalassets/offices-services/urc/jur-online/pdf/2010/brusko.cst.pdf (accessed on 12 July 2020).

32. Portello, J.Y.; Long, B.C. Gender role orientation, ethical and interpersonal conflicts, and conflict handling styles of female managers. Sex Roles 1994, 31, 682-701. [CrossRef]

33. Baxter, L.A.; Shepard, T.L. Sex-role identity, sex of other, and affective relationship as determinants of interpersonal conflict-management styles. Sex Roles 1978, 4, 813-825. [CrossRef]

34. Jurma, W.E.; Powell, M.L. Perceived gender roles of managers and effective conflict management. Psychol. Rep. 1994, 74, 104-106. [CrossRef]

35. Bem, S.L.; Lenney, E. Sex typing and the avoidance of cross-sex behavior. J. Pers. Soc. Psychol. 1976, 33, 48-54. [CrossRef]

36. Bem, S.L. The measurement of psychological androgyny. J. Consult. Clin. Psychol. 1974, 42, $155-162$. [CrossRef]

37. Rahim, A.M. A measure of styles of handling interpersonal conflict. Acad. Manag. J. 1983, 26, 368-376.

38. Ceptureanu, E.G.; Ceptureanu, S.I.; Orzan, M.C.; Bordean, O.N.; Radulescu, V. Empirical Study on Sustainable Opportunities Recognition. A Polyvinyl Chloride (PVC) Joinery Industry Analysis Using Augmented Sustainable Development Process Model. Sustainability 2017, 9, 1779. [CrossRef]

39. Sorenson, R.L. Conflict management strategies used in successful family businesses. Fam. Bus. Rev. 1999, 12, 133-146. [CrossRef]

40. Havenga, W. Gender and age differences in conflict management with small businesses. S. Afr. J. Hum. Resour. Manag. 2008, 6, 22-28. [CrossRef]

41. Babcock, L.; Laschever, S. Women Don't Ask: Negotiation and the Gender Divide; Princeton University Press: Princeton, NJ, USA, 2004.

42. Andrén, D.; Andrén, T. Gender and occupational wage gaps in Romania: From planned equality to market inequality? IZA J. Eur. Labor Stud. 2015, 4, 1-27. [CrossRef]

43. Mihuț, I.; Lungescu, D. Dimensiuni culturale în managementul românesc. Manag. Mark. 2006, 1, 5-26.

44. Smirles, K.E.S.; Basile, K.A.; Aughenbaugh, A.; Nasser, S.; Logue, S.; Arteaga, L. Japanese women's perceptions of gender roles and leadership and the effects of a Women \& Leadership Course: A qualitative analysis. Women. Stud. Int. Forum 2020, 80, 102359.

45. Dean, S.M. Characteristics of African American family-owned businesses in Los Angeles. Fam. Bus. Rev. 1992, 5, 373-395. [CrossRef]

46. Achim, M.V.; Borlea, N.; Văidean, V.L. Culture, entrepreneurship and economic development. An empirical approach. Entrep. Res. J. 2019, 1-28. [CrossRef]

47. Henning, M.; Jardim, A. The Managerial Woman; Pocket Books: New York, NY, USA, 1977.

48. Ceptureanu, S.I.; Ceptureanu, E.G.; Bogdan, V.L.; Radulescu, V. Sustainability perceptions in Romanian non-profit organizations: An exploratory study using success factor analysis. Sustainability 2018, 10, 294. [CrossRef]

(C) 2020 by the authors. Licensee MDPI, Basel, Switzerland. This article is an open access article distributed under the terms and conditions of the Creative Commons Attribution (CC BY) license (http://creativecommons.org/licenses/by/4.0/). 